\section{Maternal history of miscarriages and measures of fertility in relation to childhood asthma}

\author{
Peter G Gibson
}

The miracle of life is that conception and birth is turning out to be vitally important for airway diseases. Parental factors and events during pregnancy influence neonatal outcomes and infant bronchiolitis, ${ }^{12}$ and increase the risk of childhood asthma and adult COPD. ${ }^{34}$ Crucially, data are now emerging from randomised controlled trials that interventions during pregnancy can modify the incidence of childhood asthma. ${ }^{5-7}$ Because asthma is so common, and is manageable, this raises the possibility that asthma in pregnancy is an important and potentially modifiable risk factor for the associated adverse maternal and fetal outcomes, and for childhood asthma outcomes. This knowledge is now driving intense interest in the developmental origins of adult lung disease, and the role of interventions to prevent adult lung disease. ${ }^{8}$

What's been missing from this conversation is sex, or more specifically conception. Is there something going on here that is also relevant to the development of childhood asthma? In this issue of Thorax, the article by Maria Magnus and colleagues says the answer is yes, and then goes on to tease out some of the relevant factors (Magnus $\mathrm{M}$ et al). ${ }^{9}$ It's a little known fact that women with asthma have more trouble conceiving than non-asthmatic women. Time to pregnancy is increased in asthma, and this is particularly obvious after the age of $35 .^{1011}$ This leads to a need for assisted reproductive technologies (ART), which themselves may be associated with an increased risk of childhood asthma. ${ }^{12}$

The UK Millennium cohort study of 18818 children who were recruited at 9 months of age and prospectively followed at 5 and 7 years of age found that children who were born to subfertile parents were significantly more likely to develop asthma, and to be taking asthma medication at 5 years of age. ${ }^{12}$ This association was mainly related to an increase among children born after ART where the adjusted OR was 2.65 for asthma and 4.67

Correspondence to Dr Peter G Gibson, Respiratory and Sleep Medicine, John Hunter Hospital, Newcastle NSW 2310, Australia;

peter.gibson@hnehealth.nsw.gov.au for taking asthma medications. In this study, the effects were attenuated by age 7. So maternal asthma is associated with an increased risk of childhood asthma and subfertility, and treatment for subfertility is also associated with an increased risk of childhood asthma. Why is this? Is it the subfertility or its treatment that underlies the increased risk of childhood asthma?

To answer this question, Magnus and colleagues used an interesting data linkage design where the results of two national registries were linked and a prospective cohort study of mothers and their babies was also interrogated to address the same overall research question. The authors linked data from a national birth registry and a national prescription database to identify children born using ART and who also used asthma medication. The registries gave population-level estimates of risk, and the cohort study added granularity to the observations and potential risk factors. Their results extend the risk of ART for asthma in children out to an age of 7 years and suggest that both parental subfertility and the ART procedure itself might increase childhood asthma risk. The overall relative risk of asthma in children conceived by ART was 1.42. This is consistent with the literature to date (six other studies), which reports a risk that is between 1.28 and 2.65 (OR). Parental subfertility was associated with an increased childhood asthma risk, with an OR of 1.19. When the risk of childhood asthma after ART was compared with the risk in children born to parents who had tried to conceive for more than 12 months, as a way of controlling for the effects of parental subfertility, then an additional risk of ART was seen, with an OR of 1.22. What this says is that it is both subfertility and its treatment that are associated with an increased risk of childhood asthma. While these effect sizes are modest, their importance comes from the relatively high prevalence of both asthma and subfertility, and the potential to modify these risk factors.

Are some ARTs better than others for women with asthma? The data do not provide an answer to this question. The positive associations with childhood asthma were seen across different types of ART, including in vitro fertilisation and intracytoplasmic sperm injection. Alterations in embryo development before implantation, and in the receptivity of the endometrium, are major causes of subfertility and are the targets of assisted reproduction technologies. In ART, medications may be used to induce ovulation, cell culture procedures are required for embryo development, the hormonal environment is modified and the embryo may also be manipulated. Since these steps influence the embryo and the implantation environment, they may also modify placental and fetal growth and development, which then has implications for infant development. This raises the question of what is the best ART approach in asthma. Surely this needs further study to address whether there may be preferred ARTs for women with asthma.

What is the mechanism of these effects? The web of potential interactions is complex, and involves risks of asthma itself, pregnancy complications, subfertility and ART, all interacting to lead to an overall increased risk of asthma in the offspring. The authors favour a common immunological mechanism and cite their observation that maternal history of early miscarriages was also associated with an increased childhood asthma risk. Both miscarriage and subfertility are modulated by immune pathways, and a range of potential mechanisms has been proposed to explain these observations. ${ }^{13}$ Inducible regulatory $\mathrm{T}$ cells seem to be key players that influence events around conception and implantation, and a failure to develop $\mathrm{T}$ regulatory cell-mediated immune tolerance is associated with subfertility, recurrent miscarriage and adverse effects in the fetus and offspring.

How will we transfer this knowledge? Prospective parents with asthma and healthcare providers in the asthma and reproductive medicine areas should understand this information. At this stage, we can inform people that asthma is associated with subfertility, and that subfertility and ART are risk factors for the development of childhood asthma. We can encourage research to define the best ways to explain and manage these issues. Asthma and pregnancy seem to fall between two disciplines, and so guidelines in this area are not optimal. ${ }^{14}$ There is clearly more to do to improve what and how we communicate what we know about one of the fundamental questions that is asked by people with asthma, namely will my child get asthma? 
Preventing childhood asthma must be one of the big goals of respiratory medicine. And sex is part of the equation. There are clearly many opportunities to better define the risks of subfertility and its treatment for childhood asthma, to discover effective prevention and management strategies and to communicate this information to the people who matter.

Contributors PGG is the sole author.

Funding This study was funded by the National Health and Medical Research Council (1155810).

Competing interests None declared.

Patient consent Not required.

Provenance and peer review Commissioned; externally peer reviewed.

(C) Author(s) (or their employer(s)) 2019. No commercial re-use. See rights and permissions. Published by BMJ.

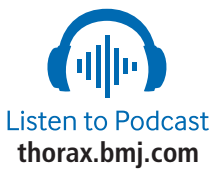

D) Check for updates
To cite Gibson PG. Thorax 2019;74:101-102.

Accepted 29 October 2018

Published Online First 4 December 2018

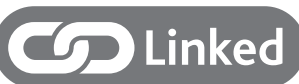

http://dx.doi.org/10.1136/thoraxjnl-2018-211886

Thorax 2019;74:101-102.

doi:10.1136/thoraxjnl-2018-212598

\section{REFERENCES}

1 Murphy VE, Wang G, Namazy JA, et al. The risk of congenital malformations, perinatal mortality and neonatal hospitalisation among pregnant women with asthma: a systematic review and meta-analysis. BJOG 2013;120:812-22.

2 Mattes J, Murphy VE, Powell H, et al. Prenatal origins of bronchiolitis: protective effect of optimised asthma management during pregnancy. Thorax 2014;69:383-4.

3 Behrooz L, Balekian DS, Faridi MK, et al. Prenatal and postnatal tobacco smoke exposure and risk of severe bronchiolitis during infancy. Respir Med 2018:140:21-6.

4 Martinez FD. Early-life origins of chronic obstructive pulmonary disease. N Engl J Med 2016;375:871-8.

5 Bisgaard H, Stokholm J, Chawes BL, et al. Fish oil-derived fatty acids in pregnancy and wheeze and asthma in offspring. N Engl J Med 2016;375:2530-9.
6 Wolsk HM, Chawes BL, Litonjua AA, et al. Prenatal vitamin $D$ supplementation reduces risk of asthma/ recurrent wheeze in early childhood: A combined analysis of two randomized controlled trials. PLoS One 2017; 12:e0186657.

7 Morten M, Collison A, Murphy VE, et al. Managing Asthma in Pregnancy (MAP) trial: FENO levels and childhood asthma. J Allergy Clin Immunol 2018;6749:30392-0.

8 Bousquet J, Anto JM, Berkouk K, et al. Developmental determinants in non-communicable chronic diseases and ageing. Thorax 2015;70:595-7.

9 Magnus M, Karlstad 0, Parr C, et al. Maternal history of miscarriages and measures of fertility in relation to childhood asthma. Thorax 2019;74:106-13.

10 Gade EJ, Thomsen SF, Lindenberg S, et al. Fertility outcomes in asthma: a clinical study of 245 women with unexplained infertility. Eur Respir J 2016;47:1144-51.

11 Gade EJ, Thomsen SF, Lindenberg S, et al. Asthma affects time to pregnancy and fertility: a register-based twin study. Eur Respir J 2014;43:1077-85.

12 Carson C, Sacker A, Kelly Y, et al. Asthma in children born after infertility treatment: findings from the UK Millennium Cohort Study. Hum Reprod 2013:28:471-9.

13 Robertson SA, Care AS, Moldenhauer LM. Regulatory $T$ cells in embryo implantation and the immune response to pregnancy. J Clin Invest 2018;128:4224-35.

14 McLaughlin K, Foureur M, Jensen ME, et al. Review and appraisal of guidelines for the management of asthma during pregnancy. Women Birth 2018;5192:30512-7. 